Med Clin North Am. 2012 January ; 96(1): 87-91. doi:10.1016/j.mcna.2011.11.003.

\title{
Age as a Cardiovascular Risk Factor
}

\author{
Ravi Dhingra, MD, MPH and \\ Instructor of Medicine, Dartmouth Medical School, Section of Cardiology, Heart and Vascular \\ Center, Dartmouth Hitchcock Medical Center, One Medical Center Drive, Lebanon, NH 03765, \\ Tel. 603-650-6224, Fax. 603-650-0523
}

\section{Ramachandran S. Vasan, MD, DM, FACC, FAHA}

Chief, Section of Preventive Medicine and Epidemiology, Dept. of Medicine, Professor of Medicine, Boston University, School of Medicine, The Framingham Heart Study, 73 Mount Wayte Avenue, Suite 2, Framingham, MA 01702-5803, Tel. 508-935-3450, Fax. 508-626-1262

Ravi Dhingra: ravi.dhingra@hitchcock.org; Ramachandran S. Vasan: vasan@bu.edu

\author{
Keywords \\ Age; Cardiovascular disease; Risk
}

It is not by the gray of the hair that one knows the age of the heart.

$\sim$ Edward Bulwer-Lytton

\section{Introduction}

According to the most recent estimates from United States, cardiovascular disease (CVD) death rates have declined but the disease burden still remains substantially high. ${ }^{1}$ The risk of developing CVD is largely (75-90\%) explained by the presence or absence of traditional CVD risk factors. ${ }^{2}$ Age is a well known traditional risk factor, which is generally considered to be non-modifiable for obvious reasons. In this review, we discuss the common use of an individual's age in prediction of CVD incidence using different risk scores, examine whether age as a risk factor can be modified or not, discuss the methods used to evaluate long- and short-term CVD risk, appropriate communication of an individual's risk based on their age group and CVD risk, and conclude by discussing the influence of age on cardiac and vascular risk factors.

\section{Assessment of CVD risk using Age as part of Risk Scores}

With aging, there is an incremental acquisition of several CVD risk factors in an individual's lifespan. When these risk factors are incorporated in a multivariable regression model, age still remains an independent risk factor. There are several risk prediction scores currently available to assess an individual's risk of CVD, and all of them include 'age' as a predictor. Older age, as assessed by these risk scores, is associated with greater risk of CVD.

\footnotetext{
(c) 2011 Elsevier Inc. All rights reserved.

Correspondence to: Ramachandran S. Vasan, vasan@bu. edu.

Disclosures: None
}

Publisher's Disclaimer: This is a PDF file of an unedited manuscript that has been accepted for publication. As a service to our customers we are providing this early version of the manuscript. The manuscript will undergo copyediting, typesetting, and review of the resulting proof before it is published in its final citable form. Please note that during the production process errors may be discovered which could affect the content, and all legal disclaimers that apply to the journal pertain. 
Although there are several risk scores available, the Framingham Risk Score (FRS) ${ }^{3}$ is one of the most-widely adopted screening tools in United States and is recommended by National Heart Lung and Blood Institute to assess an individual's CVD risk. ${ }^{4,5}$ Other risk scores which are tested in Britain, ${ }^{6}$ Scotland, ${ }^{7}$ New Zealand ${ }^{8}$ or China ${ }^{9}$ have not been formally tested in the United States. In addition to the traditional risk factors (age, gender, smoking, total cholesterol, HDL-cholesterol and systolic blood pressure which are part of FRS), risk scores developed in Britain and Scotland also incorporate family history and social deprivation as risk factors, and these additional variables marginally improve prediction of CVD risk over the FRS when applied to the British and the Scottish populations, respectively. The Reynolds risk score also includes age as a component and is constructed using a database of middle-aged American women and requires the additional measurements of C-reactive protein and HbA1c (in diabetics).$^{10}$ Lastly, the risk prediction score reported in prior European studies ${ }^{11}$ and currently adopted by the Joint European societies ${ }^{12}$ is based on models which predict CVD death, and therefore underestimates the burden of CVD by not including the non-fatal events. Note that although CVD death rates have declined in some developed European countries (quite similar to the trend in the United States), the overall CVD burden still remains high.

\section{Age is an Independent Risk Factor for Cardiovascular Disease}

As discussed above, even after adjusting for traditional risk factors in a multivariable CVD prediction model, age remains a fundamental predictor of CVD risk. However, when age and other risk factors are used jointly to examine an individual's future risk of CVD, it has been postulated that the contribution of age in the multivariable models may be a reflection of the intensity and the duration of exposure to other traditional CVD risk factors. ${ }^{13}$ If this observation were true, avoidance of these other risk factors should result in a reduction of CVD risk associated with age per se. To examine this hypothesis prior studies from Framingham Heart Study have shown that the absence of each of these traditional risk factors is associated with a reduction in the risk of CVD even at an older age. ${ }^{14}$ When the absence of multiple risk factors is factored into an individual's CVD risk assessment, the reduction in CVD risk is further augmented. Similarly, using the Framingham cohort, investigators have observed that lower midlife blood pressure and total cholesterol levels, absence of glucose intolerance, smoking abstinence, higher education and female gender all predicted increased survival up to 85 years of age. ${ }^{15}$ Additionally at an older age, the contribution of age to CVD risk prediction declines, in part because there is less time left for an individual to acquire other modifiable CVD risk factors. Therefore, age at any given point influences the assessment of both the short- and long-term CVD risk of an individual. The absence of these CVD risk factors not only prevents the development of CVD but also decreases the risk of age-associated co-morbidities and mortality. ${ }^{15}$ In another prior study, after excluding individuals with cancer, cardiovascular disease and diabetes before 50 years of age, investigators followed the Framingham cohort to evaluate who was likely to reach 75 years of age. They concluded that smoking fewer cigarettes per day, lower systolic blood pressure, and higher forced vital capacity were associated with longevity in both sexes. ${ }^{16}$ Moreover, these observations relating to presence and absence of traditional risk factors have also been confirmed in a population-based study in the Japanese cohort from the Honolulu Heart Program, ${ }^{17}$ and the large scale, multiethnic and international InterHeart Study. ${ }^{18}$ The InterHeart study investigators also tested this hypothesis in a case-control fashion among all age groups and observed similar results for prevention of myocardial infarction. ${ }^{18}$ Therefore, it is now well established that life expectancy of an individual is dependent on modification of traditional risk factors and age-associated risk of CVD can be minimized by correcting or avoidance of these risk factors. Though, it is important to note that risk factor modification is equally important for both young and older individuals, and will decrease their subsequent risk of CVD. 


\section{Relative risk versus Absolute risk Assessment}

Current CVD risk assessment using Framingham risk score comprises of the traditional risk factors i.e. cholesterol (total and HDL), blood pressure, history of smoking and age. ${ }^{5,19}$ While assessing risk of CVD, it is important that both short-term (10-year CVD risk) and long-term ( $>10$ year) risk for CVD are evaluated, and communicated appropriately to an individual. ${ }^{20}$ At a younger age, an individual with several CVD risk factors (i.e. smoker, increased cholesterol and high blood pressure) will have a lower absolute short-term risk (compared to an older individual with similar CVD risk factors), and the absolute risk increases as the person gets older. However, the relative risk remains relatively invariant throughout a person's lifespan provided other risk factors (except age) do not change, and it may actually decrease over time. Similarly, an older individual with several risk factors will have a higher short-term absolute risk (compared to a younger individual with a similar risk factor profile) even though the relative risk may remain constant through the lifespan, provided there is no change in risk factors.

\section{Communicating CVD Risk to Young and Old}

Communicating either short- or long-term CVD risk to a patient can be challenging and might over or under-estimate the importance of risk factor reduction and therefore impact how a person would react by changing lifestyle for future risk reduction. For example, communicating an overestimated relative risk to a young individual might result in emotional or financial stress (may require them to take medications) whereas communicating an under-estimated absolute risk may result in a lower level of motivation on the part of an individual to work towards changing his/her lifestyle to reduce CVD risk. ${ }^{21}$

Present guidelines from Adult Treatment Panel (ATP-III) for treatment of high blood cholesterol appropriately incorporates both relative and absolute risk assessment aspects (as discussed above) for an individual and provides flexibility for discussion by a treating physician in primary prevention settings. ${ }^{4,5}$ Prior investigators have cautioned treating physicians to distance themselves from communicating the magnified relative risk of an individual (compared to lower absolute risk) in order to achieve professionally desirable goals. ${ }^{21}$

\section{Influence of Age on Other Individual Risk Factors}

It is intuitive that if age is an independent risk factor for developing CVD, the lifetime risk of CVD for an individual would continue to increase with age. However, the lifetime risk for CVD is lower at age 70 than at age 50 years, for an individual whose lifestyle risk factors remains unchanged. ${ }^{14}$ Similarly, lifetime risk of coronary artery disease, ${ }^{22}$ stroke, ${ }^{23}$ hypertension ${ }^{24}$ and heart failure ${ }^{25}$ does not continue to increase with age. One explanation for this observation is that there is shorter time period left for older individuals to develop the disease and a greater hazard of death due to competing causes. Other reasons are that those who live longer have inherent bias of lower burden of cardiovascular risk factors which lowers their risk of developing an event, or a genetic makeup with resistance to develop cardiovascular disease. Framingham cohort enrolled individuals at their midlife (30-62yrs) primarily but InterHeart study included some young participants ( $<40 \mathrm{yrs})$ and both showed similar results that reduction or absence of risk factors is additive and improves mortality. Consequently, it is important to note that screening for risk factors and advice about modifications of risk factors should start at an early age. 


\section{Influence of Individual Risk Factors on Age-associated CVD Risk}

A sex-specific analysis from Framingham cohort suggests about 11.9\% ( men) to $40.3 \%$ (women) of age-associated CVD risk may be attributable to the concomitant burden of other CVD risk factors. ${ }^{26}$ These estimates are based on comparing unadjusted regression coefficients for age with those obtained after adjusting for other CVD risk factors in multivariable models (systolic blood pressure, diabetes, total to high-density lipoprotein cholesterol ratio, history of smoking and body mass index).

\section{Conclusion}

The risk of developing CVD is generally dependent on the presence or absence of traditional risk factors. Increasing age is an independent risk factor for CVD, however. The burden of CVD risk associated with rising age can be reduced partly by the modification of traditional coexisting CVD risk factors. When communicating an individual's CVD risk regardless of age, both short-term (10-year) and long-term (>10 years) risks (both absolute and relative risks) should be discussed and the subsequent management of CVD risk factors should be individualized.

\section{Acknowledgments}

This work was supported by contract NO1 25195 from the National Institute of Health

\section{References}

1. Roger VL, Go AS, Lloyd-Jones DM, et al. Heart Disease and Stroke Statistics - 2011 Update: A Report From the American Heart Association. Circulation. 2011; 123:e18-e209. [PubMed: 21160056]

2. Vasan RS, Sullivan LM, Wilson PWF, et al. Relative Importance of Borderline and Elevated Levels of Coronary Heart Disease Risk Factors. Ann Intern Med. 2005; 142:393-41. [PubMed: 15767617]

3. D'Agostino RB, Vasan RS, Pencina MJ, et al. General Cardiovascular Risk Profile for Use in Primary Care. Circulation. 2008; 117:743-753. [PubMed: 18212285]

4. Executive Summary of the Third Report of the National Cholesterol Education Program (NCEP) Expert Panel on Detection, Evaluation, and Treatment of High Blood Cholesterol in Adults (Adult Treatment Panel III). JAMA. 2001; 285:2486-2497. [PubMed: 11368702]

5. Grundy SM, Cleeman JI, Merz CNB, et al. Implications of Recent Clinical Trials for the National Cholesterol Education Program Adult Treatment Panel III Guidelines. Circulation. 2004; 110:227239. [PubMed: 15249516]

6. Hippisley-Cox J, Coupland C, Vinogradova Y, et al. Derivation and validation of QRISK, a new cardiovascular disease risk score for the United Kingdom: prospective open cohort study. BMJ. 2007; 335:136. [PubMed: 17615182]

7. Woodward M, Brindle P, Tunstall-Pedoe H. Adding social deprivation and family history to cardiovascular risk assessment: the ASSIGN score from the Scottish Heart Health Extended Cohort (SHHEC). Heart. 2007; 93:172-176. [PubMed: 17090561]

8. Jackson R. Updated New Zealand cardiovascular disease risk-benefit prediction guide. BMJ. 2000; 320:709-710. [PubMed: 10710588]

9. Zhang XF, Attia J, D'Este C, et al. A risk score predicted coronary heart disease and stroke in a Chinese cohort. J Clin Epidemiol. 2005; 58:951-958. [PubMed: 16085199]

10. Ridker PM, Buring JE, Rifai N, et al. Development and Validation of Improved Algorithms for the Assessment of Global Cardiovascular Risk in Women. JAMA. 2007; 297:611-619. [PubMed: 17299196]

11. Conroy RM, Pyörälä K, Fitzgerald AP, et al. Estimation of ten-year risk of fatal cardiovascular disease in Europe: the SCORE project. Eur Heart J. 2003; 24:987-1003. [PubMed: 12788299] 
12. Graham I, Atar D, Borch-Johnsen K, et al. European guidelines on cardiovascular disease prevention in clinical practice: executive summary. Eur Heart J. 2007; 28:2375-2414. [PubMed: 17726041]

13. Sniderman AD, Furberg CD. Age as a modifiable risk factor for cardiovascular disease. Lancet. 2008; 371:1547-1549. [PubMed: 18321568]

14. Lloyd-Jones DM, Leip EP, Larson MG, et al. Prediction of Lifetime Risk for Cardiovascular Disease by Risk Factor Burden at 50 Years of Age. Circulation. 2006; 113:791-798. [PubMed: 16461820]

15. Terry DF, Pencina MJ, Vasan RS, et al. Cardiovascular Risk Factors Predictive for Survival and Morbidity-Free Survival in the Oldest-Old Framingham Heart Study Participants. J Am Geriatr Soc. 2005; 53:1944-1950. [PubMed: 16274376]

16. Goldberg RJ, Larson M, Levy D. Factors Associated With Survival to 75 Years of Age in Middleaged Men and Women: The Framingham Study. Arch Intern Med. 1996; 156:505-509. [PubMed: 8604956]

17. Willcox BJ, He Q, Chen R, et al. Midlife Risk Factors and Healthy Survival in Men. JAMA. 2006; 296:2343-2350. [PubMed: 17105797]

18. Yusuf S, Hawken S, Ônpuu S, et al. Effect of potentially modifiable risk factors associated with myocardial infarction in 52 countries (the INTERHEART study): case-control study. Lancet. 2004; 364:937-952. [PubMed: 15364185]

19. D'Agostino RB, Vasan RS, Pencina MJ, et al. General Cardiovascular Risk Profile for Use in Primary Care. Circulation. 2008; 117:743-753. [PubMed: 18212285]

20. Vasan RS, D'Agostino RB. Age and Time Need Not and Should Not Be Eliminated From the Coronary Risk Prediction Models. Circulation. 2005; 111:542-545. [PubMed: 15699273]

21. Epstein RM, Alper BS, Quill TE. Communicating Evidence for Participatory Decision Making. JAMA. 2004; 291:2359-2366. [PubMed: 15150208]

22. Lloyd-Jones DM, Larson MG, Beiser A, et al. Lifetime risk of developing coronary heart disease. Lancet. 1999; 353:89-92. [PubMed: 10023892]

23. Seshadri S, Beiser A, Kelly-Hayes M, et al. The Lifetime Risk of Stroke. Stroke. 2006; 37:345350. [PubMed: 16397184]

24. Vasan RS, Beiser A, Seshadri S, et al. Residual Lifetime Risk for Developing Hypertension in Middle-aged Women and Men. JAMA. 2002; 287:1003-1010. [PubMed: 11866648]

25. Lloyd-Jones DM, Larson MG, Leip EP, et al. Lifetime Risk for Developing Congestive Heart Failure. Circulation. 2002; 106:3068-3072. [PubMed: 12473553]

26. Kannel WB, Vasan RS. Is Age Really a Non-Modifiable Cardiovascular Risk Factor? Am J Cardiol. 2009; 104:1307-1310. [PubMed: 19840582] 


\section{Synopsis}

The risk of developing CVD is generally dependent on the presence or absence of traditional risk factors. Age is a well known traditional risk factor, which is generally considered to be non-modifiable for obvious reasons. In this review, we discuss the common use of an individual's age in prediction of CVD incidence using different risk scores, examine whether age as a risk factor can be modified or not, discuss the methods used to evaluate long- and short-term CVD risk, appropriate communication of an individual's risk based on their age group and CVD risk, and conclude by discussing the influence of age on cardiac and vascular risk factors 